13 Albers JJ, Warnick GR, Wiebe D, et al. Multi-laboratory comparison of three heparin- $\mathrm{Mn}^{2+}$ precipitation procedures for estimating cholesterol in high-density lipoprotein. Clin Chem 1978;24:853-6.

${ }^{14}$ Alaupovic P, Curry MD, McConathy WJ. Quantitative determination of human plasma apolipoproteins by electroimmunoassays. In: Carlson LA, Paoletti R, Sirtori CR, Weber G, eds. International conference on atherosclerosis. New York: Raven Press, 1978:109-15.

15 Anonymous. Antihypertensive drugs, plasma lipids and coronary disease. Lancet 1980;ii:19-20.

16 Gotto AM Jr, Miller NE, Oliver MF, eds. High density lipoproteins and atherosclerosis. Amsterdam: Elsevier/North-Holland, 1978.

17 Solberg LA, Enger SC, Hjermann I, et al. Risk factors for coronary and cerebral atherosclerosis in the Oslo study. In: Gotto AM, Smith LC Allen B, eds. Atherosclerosis V. Berlin: Springer-Verlag, 1980:57-62.

${ }^{18}$ Gofman JW, Young W, Tandy R. Ischemic heart disease, atherosclerosis and longevity. Circulation $1966 ; 34: 679-97$.

${ }^{19}$ Albers JJ, Cheung MC, Hazzard WR. High-density lipoproteins in myocardial infarction survivors. Metabolism 1978;27:479-85.

20 Gofman JW, DeLalla O, Glazier F, et al. The serum lipoprotein transport system in health, metabolic disorders, atherosclerosis and coronary heart disease. Plasma $1954 ; 2: 413-84$.

${ }^{21}$ Fredrickson DS, Levy RI, Lees RS. Fat transport in lipoproteins-an integrated approach to mechanisms and disorders. $N$ Engl $\mathcal{F ~} \mathrm{Med}$ $1967 ; 276$ :34-44.
22 Zilversmit DB. Atherogenesis: a postprandial phenomenon. Circulation w $1979 ; 60: 473-85$

${ }^{23}$ Ishikawa T, Fidge N, Thelle DS, Førde OH, Miller NE. The Tromsø Heart Study: serum apolipoprotein AI concentration in relation to 2 future coronary heart disease. Eur f Clin Invest 1978;8:179-82.

${ }^{24}$ Avogaro P, Bittolo Bon G, Cazzolato G, Quinci GB. Are apolipoproteins $\widehat{\Omega}$ better discriminators than lipids for atherosclerosis? Lancet 1979; i: 901-3.

${ }^{25}$ Nikkila EA. Metabolic and endocrine control of plasma high density $\underset{\mathbb{D}}{\mathbb{D}}$ lipoprotein concentration. Relation to catabolism of triglyceride-rich o lipoproteins. In: Gotto $\mathrm{AM} \mathrm{Jr}$, Miller NE, Oliver $\mathrm{MF}$, eds. High $\varrho$ density lipoproteins and atherosclerosis. Amsterdam: Elsevier/North- Holland, 1978:177-92.

${ }^{26}$ Weisgraber $\mathrm{KH}$, Mahley RW. Subfractionation of human high density $\stackrel{\vec{P}}{\vec{S}}$ lipoproteins by heparin-Sepharose affinity chromatography. $\mathcal{f}$ Lipid Res $1980 ; 21: 316-25$.

${ }^{27}$ Suenram A, McConathy WJ, Alaupovic P. Evidence for the lipoprotein $\overline{\bar{C}}$ heterogeneity of human plasma high density lipoproteins isolated by $\vec{D}$ three different procedures. In: Lindgren FT, Nichols AV, Krauss RM, 凤 eds. High density lipoproteins. Champaign, Illinois: American Oil \& Chemists Society, 1979:36-41.

(Accepted 2 April 1981)

\title{
Hepatic vascular lesions associated with dacarbazine treatment
}

\author{
M A GREENSTONE, PAULINE M DOWD, D P MIKHAILIDIS, P J SCHEUER
}

\begin{abstract}
Dacarbazine is widely used in the treatment of melanoma. Transient abnormalities of liver function tests are well-recognised side effects of the drug, but acute liver failure due to vascular occlusion in patients receiving single-agent chemotherapy with dacarbazine has been noted only rarely. Two cases are reported in which hepatic vascular lesions developed during treatment with dacarbazine and were confirmed at necropsy.

Hepatic vascular occlusion due to treatment with dacarbazine may be less rare than was previously thought. Greater caution may be needed when dacarbazine is prescribed, particularly as an adjuvant agent in stage I and II disease.
\end{abstract}

\section{Introduction}

Dacarbazine (dimethyl-triazeno-imidazole-carboxamide) has been widely used in the treatment of stage III melanoma and in trials of adjuvant chemotherapy in patients with stage I and II disease with a poor prognosis. We report two cases in which hepatic vascular lesions occurred during dacarbazine treatment.

\footnotetext{
Departments of Oncology and Dermatology, Royal Marsden Hospital, London SW3
}

M A GREENSTONE, MB, MRCP, senior house officer (present address : department of medicine, St Mary's Hospital, London W2)

PAULINE M DOWD, BSC, MRCP, honorary registrar (present address department of dermatology, St Bartholomew's Hospital, London EC1)

D $\mathbf{P}$ MIKHAILIDIS, BSC, $\mathrm{MB}$, senior house officer (present address : department of chemical pathology, Royal Free Hospital, London NW3)

Department of Histopathology, Royal Free Hospital, London NW3 P J SCHEUER, MD, FRCPATH, professor of clinical histopathology

\section{Case reports}

CASE 1

A 53-year-old Caucasian man developed histologically proved lymph-node metastases five years after wide excision of primary melanoma. In April 1978 he began treatment with dacarbazine (250 $\mathrm{mg} / \mathrm{m}^{2}$ daily for five days). He was also taking amitryptiline $\overrightarrow{\bar{B}}$ (Lentizol) $50 \mathrm{mg}$ at night and chlorpromazine as required as an antiemetic. Apart from transient fever on the fifth day, he tolerated treatment well. One month later he was readmitted for a second course of dacarbazine. He was well, and clinical examination, full blood count, urea and electrolyte concentrations, and liver function tests were all normal. His medication was as before. He remained well until the fourth day of treatment, when he developed acute abdominal pain and hepatic tenderness. He deteriorated with confusion, jaundice, and hypotension. Results of liver function tests became extremely abnormal (aspartate transaminase activity $1780 \mathrm{U} / 1$, alkaline phosphatase activity $148 \mathrm{IU} / 1$, total bilirubin $77 \mu \mathrm{mol} / \mathrm{l}$ $(4.5 \mathrm{mg} / 100 \mathrm{ml})$ ), and he developed prolonged prothrombin and partial thromboplastin times, hypoglycaemia, and a profound meta- $N$ bolic acidosis. A peripheral blood film showed only mild neutrophilia $D$ $\left(74 \%\right.$ of $\left.13.9 \times 10^{9} / 1\right)$, whereas a differential white cell count two 을. days earlier had shown eosinophilia of $17 \%$ of $7 \times 10^{9} / 1$. Blood cultures were repeatedly negative. Despite vigorous supportive treatment he died 72 hours later.

At necropsy the liver had a mottled red appearance and irregular $\sigma$ areas of necrosis were seen. The main hepatic and portal veins were 0 patent. On microscopy recent infarcts were associated with fresh $\frac{\bar{D}}{\bar{D}}$

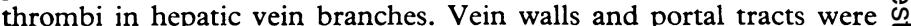
infiltrated with lymphocytes and eosinophils. There was a microscopic metastasis in one lung.

CASE 2

A 46-year-old Caucasian man was treated with dacarbazine $500 \mathrm{mg}$ 음 intravenously daily for five days for metastatic melanoma. He tolerated the first course of treatment well but on the third day of the second course developed clinical and laboratory manifestations of acute $\stackrel{\partial}{\supset}$ hepatic necrosis. There was no clinical evidence of drug hyper- 
sensitivity (for example, skin eruption), but eosinophil counts were not available. He died about 72 hours later. No other cytotoxic agents had been administered.

Necropsy disclosed no thrombi in major vessels but showed recent hepatic infarcts, and thrombi were seen in portal and hepatic vein branches on microscopy (figure). Metastases were present in the heart, lung, pancreas, and kidneys.

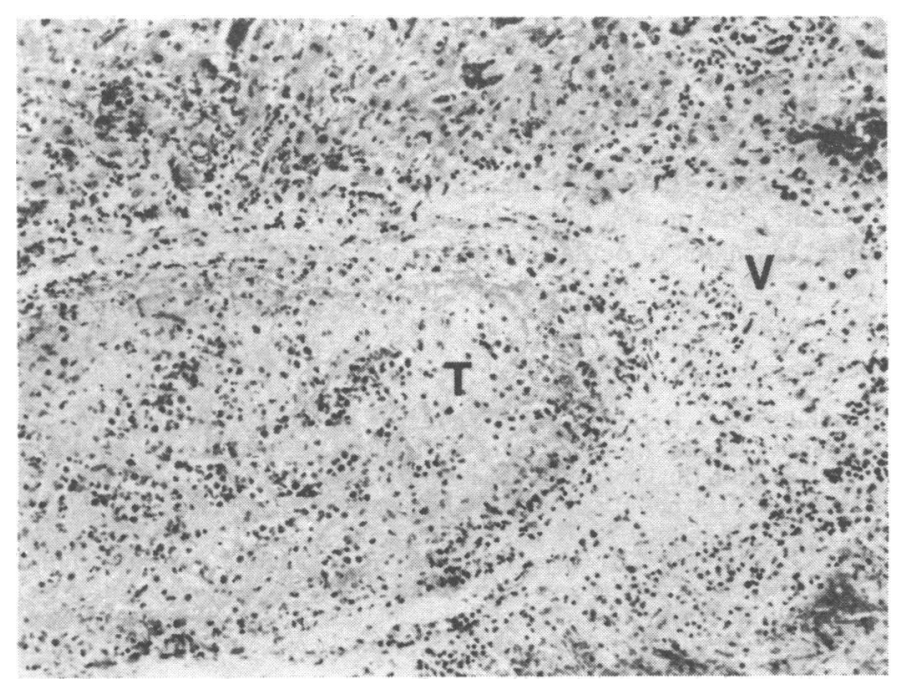

Recently formed thrombus (T) in hepatic vein branch (V). Haematoxylin and eosin $\times 180$ (original magnification).

\section{Discussion}

Transient abnormalities of liver function tests are recognised side effects of dacarbazine treatment. ${ }^{1}$ To our knowledge acute liver failure due to vascular occlusion in patients receiving single-agent chemotherapy with dacarbazine has been reported in only one case. ${ }^{2}$ Our patients showed broadly similar clinical, laboratory, and histological features. The temporal relation to dacarbazine treatment, the absence of any other identifiable cause, and the histological dissimilarity to the rare hepatic lesions attributed to chlorpromazine and amitryptiline incriminate dacarbazine. A synergistic adverse drug reaction cannot, however, be excluded. The eosinophilia in case 1, which suggests a drug reaction, was transient and preceded clinical deterioration. Eosinophil counts during each course of treatment may therefore be valuable in the early detection of liver damage.

One of us (PJS) reviewed the histology of a further patient receiving dacarbazine in whom hepatic vein thrombosis had led to the Budd-Chiari syndrome. We are also aware of five other deaths after hepatic vascular occlusions in patients receiving dacarbazine as part of multiple-agent chemotherapy ${ }^{3}$ (J S Goodall, Miles Laboratories, personal communication). We suggest that this complication of dacarbazine treatment may not be as rare as was previously thought. ${ }^{2}$ In view of this greater caution may be needed when considering the use of dacarbazine, especially as an adjuvant agent in stage I and II disease.

We thank Dr J D Everall for permission to publish the clinical details; Dr A Levene for access to postmortem material in case 1 the Ministry of Defence for permission to publish the details of case 2; and the late $\operatorname{Dr} \mathrm{J} \mathrm{S}$ Goodall of Miles Laboratories for his help.

\section{References}

${ }^{1}$ Johnson RO, Metter G, Wilson W, Hill G, Krementz E. Phase I evaluation of DTIC (NSC45388) and other studies in malignant melanoma in the central oncology group. Cancer Treat Rep 1976;60:183-7.

2 Asbury RF, Rosenthal SN, Descalzi ME, et al. Hepatic veno-occlusive disease due to DTIC. Cancer $1980 ; 45: 2670-4$.

${ }^{3}$ Lehrner LM, Enck RE. Hepatic vein thrombosis after chemotherapy for histiocytoma. Ann Intern Med 1978;88(4):575-6.

4 Hoghton AN, Shafi N, Rickles FR. Acute hepatic vein thrombosis occurring during therapy for Hodgkin's disease. Cancer 1979;44: 2324-9.

(Accepted 18 March 1981)

\title{
Retinal vasculitis in rheumatoid arthritis
}

\author{
M F R MARTIN, D G I SCOTT, C GILBERT, P A DIEPPE, D L EASTY
}

\begin{abstract}
A woman with exacerbation of severe rheumatoid arthritis developed lesions compatible with retinal vasculitis. Laboratory studies confirmed the diagnosis, and the rapid clinical improvement that accompanied a fall in circulating immune complexes suggested that the vasculitis was a direct consequence of the rheumatoid disease.

From these observations retinal vasculitis should probably be sought in any patient with rheumatoid disease
\end{abstract}

\section{Bristol Royal Infirmary, Bristol BS2 8HW}

M F R MARTIN, MRCP, senior registrar

D G I SCOTT, MRCP, medical registrar

P A DIEPPE, MRCP, consultant rheumatologist

Bristol Eye Hospital, Bristol BS1 2LX

C GILBERT, FRCs, senior registrar

D L EASTY, FRCS, consultant ophthalmologist and the vasculitis added to the list of ocular complications of rheumatoid arthritis.

\section{Introduction}

We report a case of severe rheumatoid arthritis with high concentrations of circulating immune complexes, nailfold vasculitis, and transient lesions consistent with retinal vasculitis.

\section{Case history}

A 51-year-old white woman with a history of pulmonary tuberculosis developed rheumatoid arthritis in 1965; this was complicated by recurrent scleritis $(1971,1976)$, keratoconjunctivitis sicca (1976), sensory peripheral neuropathy (1971), and rheumatoid nodules. She presented in September 1979 with an exacerbation of the rheumatoid arthritis while taking penicillamine $500 \mathrm{mg}$ and prednisolone $5 \mathrm{mg}$ daily. She reported increased joint pain and stiffness, night sweats, weight loss, and diminished visual acuity. Examination showed active 